\title{
Systematic review and meta-analysis of the utility of Iong non-coding RNA GAS5 as a diagnostic and prognostic cancer biomarker
}

\author{
Wei Li ${ }^{1}$, Na Li ${ }^{2}$, Ke Shi ${ }^{1}$ and Qiong Chen ${ }^{1}$ \\ ${ }^{1}$ Department of Geriatrics, Xiangya Hospital of Central South University, Changsha 410008, Hunan Province, China \\ ${ }^{2}$ Department of Pathology, The First Affiliated Hospital of Hunan University of Medicine, Huaihua 418000, Hunan Province, China \\ Correspondence to: Ke Shi, email: csushike@163.com \\ Qiong Chen, email: qiongch@163.com
}

Keywords: GAS5, cancer, clinical outcome, diagnosis, prognosis

Received: April 13, $2017 \quad$ Accepted: June 20, $2017 \quad$ Published: July 06, 2017

Copyright: Li et al. This is an open-access article distributed under the terms of the Creative Commons Attribution License 3.0 (CC BY 3.0), which permits unrestricted use, distribution, and reproduction in any medium, provided the original author and source are credited.

\section{ABSTRACT}

The growth arrest-specific 5 transcript (GAS5) is a long non-coding RNA (IncRNA) involved in the control of cell cycle progression and apoptosis in a wide variety of cells. To determine the clinical value of GAS5 expression in cancer patients, we performed a systematic review and meta-analysis exploring its association with the diagnosis, prognosis, and clinicopathological characteristics of cancer. Ten articles on prognosis, 15 on clinicopathology, and 5 on diagnosis were analyzed. Overall results showed that decreased GAS5 expression associated with unfavorable overall survival (OS) $(\mathrm{HR}=2.50,95 \% \mathrm{CI}: 1.85-3.38, P<0.001)$ and disease-free survival (DFS) ( $\mathrm{HR}=\mathbf{2 . 2 4}, 95 \% \mathrm{CI}: 1.58-3.18, P<0.001)$ in several tumor types. Down-regulation of GAS5 correlated with poor recurrence-free survival (RFS) in hepatocellular carcinoma ( HR = 2.40, 95\%CI: 1.27-4.54, $P=0.007)$, and was associated with lymph node metastasis (OR = 1.92, 95\% CI: 1.44-2.57, $P<0.001$ ), distant metastasis (OR = 2.7, 95\% CI: 1.05-6.97, $P=0.040$ ), poor clinical stage (OR $=0.26,95 \%$ CI: $0.18-0.38$, $P<0.001$ ), larger tumor size (OR = 3.21, 95\% CI: $2.08-4.95, P<0.001$ ), and poor tumor differentiation (OR $=1.98,95 \%$ CI: $1.40-2.80, P<0.001)$. Pooled results of diagnostic data analysis showed that GAS5 exhibited a sensitivity of 0.76 and specificity of 0.64 for cancer diagnosis, and an area under the curve of 0.76 (95\% CI: 0.72-0.80) indicated moderate diagnostic accuracy. This meta-analysis suggests GAS5 IncRNA may be a useful diagnostic and prognostic cancer biomarker, and may be especially useful for identifying patients prone to developing lymph node or distant metastasis.

\section{INTRODUCTION}

Growth arrest-specific transcript 5 (GAS5) is a widely expressed long non-coding RNA (lncRNA) transcript of about $630 \mathrm{nt}$ in length, encoded by the GAS5 gene located on chromosome 1q25. This lncRNA was initially isolated from a subtraction cDNA library of growth-arrested cells and identified as a potential new tumor inhibitor [1]. GAS5 stimulates apoptosis during serum starvation or growth factor deprivation by acting as a glucocorticoid response element (GRE) decoy, competing with GRE sequences in the DNA for binding to the glucocorticoid receptor (GR) [2]. Studies like the one by Mourtada-Maarabouni et al., showing that overexpression of IncRNA GAS5 induces apoptosis and slows the cell cycle in human T-cell lines [3] have reinforced the notion that lncRNA GAS5 plays a key role in cell growth arrest and apoptosis.

In recent years, lncRNA GAS5 has attracted considerable interest due to evidence indicating that its downregulation in a wide variety of neoplasms, including ovarian cancer $[4,5]$, prostate cancer $[6,7]$, non-small 
cell lung cancer $[8,9]$, gastric cancer $[10,11]$, colorectal cancer $[12,13]$, and hepatocellular carcinoma $[14,15]$, is generally associated with poor prognosis [10-14]. Several studies also demonstrated that upregulation of GAS5 expression inhibits tumor cell proliferation and promotes apoptosis [5-8, 12, 14-16]. By interacting with many biological molecules, including certain steroid hormone receptors and miRNAs, GAS5 modulates gene expression and impacts pivotal regulatory pathways of cell survival [17]. These discoveries are consistent with lncRNA GAS5 being a ubiquitous tumor suppressor and prognosis marker.

However, due to insufficient sampling and/or methodological limitations, published studies on the association of lncRNA GAS5 with cancer are often inaccurate and/or inadequate. To address this shortcoming, we systematically collected all relevant publications and conducted the present meta-analysis addressing the relation between GAS5 expression and cancer diagnosis, clinicopathological characteristics, and clinical outcomes. Our overall results confirm a correlation between reduced GAS5 expression and poor clinical outcomes, and reveal an association with increased likelihood of lymph node metastasis (LNM) and distant metastasis (DM) in patients with early stage tumors.

\section{RESULTS}

\section{Study characteristics}

A total of 343 potentially relevant articles were retrieved from Embase, PubMed, Web of Science, and China Knowledge Resource Integrated (CNKI) databases. After removing duplicates, 163 records were preserved. Following title and abstract revision, 131 records were excluded. Subsequently, from the 32 remaining studies 11 were excluded due to incomplete data. Finally, a total of 21 studies, including 10 on prognosis [4, 9-12, 14-16, $18,19], 15$ on clinicopathological features $[4-6,8,10-12$, $14,15,18-23]$, and 5 on diagnosis [13, 23-26], met the criteria used for inclusion in the meta-analysis (Figure 1). All 21 studies came from China, and addressed 8 different tumor types: hepatocellular carcinoma (HCC), non-small cell lung cancer (NSCLC), ovarian cancer (OC), colorectal cancer (CRC), gastric cancer (GC), cervical cancer (CC), bladder transitional cell carcinoma (BTCC), and multiple myeloma (MM). In all cases GAS5 expression was detected by qRT-PCR.

\section{Correlation of GAS5 expression with clinical outcome}

A relationship between GAS5 expression and overall survival (OS) was detected in 8 studies comprising 507 patients (Table 1). The pooled HR indicated a negative association between GAS5 expression and OS $(\mathrm{HR}=2.50,95 \% \mathrm{CI}: 1.85-3.38, P<0.001$; fixed effects model) (Figure 2). A sensitivity analysis was carried out to evaluate the robustness of the merged results, which were not significantly affected by exclusion of any single study. This indicated that the pooled OS HR was robust (Figure 3). A Begg's funnel plot test (Figure 4) further showed no obvious publication bias between the included studies $(\operatorname{Pr}>|z|=0.536)$. We also performed subgroup analyses according to cancer type. As shown in Figure 5, compared with the pooled HR for all cancers, GAS5 displayed a stronger correlation with poor OS in the subgroups of reproductive system tumors $(\mathrm{HR}=2.80$, 95\% CI: 1.56-5.02, $P<0.001)$, and in $\mathrm{HCC}(\mathrm{HR}=2.77$, 95\% CI: $1.57-4.90, P<0.001)$.

Three studies including 234 patients reported HRs for disease-free survival (DFS). The overall result revealed that decreased GAS5 expression could predict poor DFS $(\mathrm{HR}=2.24,95 \% \mathrm{CI}: 1.58-3.18, P<0.001)$ (Figure 2). Only one study, comprising 71 patients, reported HR for recurrence-free survival (RFS). In such report, downregulation of GAS5 also correlated with poor RFS $(\mathrm{HR}=2.40,95 \% \mathrm{CI}: 1.27-4.54, P=0.007)$ (Figure 2).

Hepatocellular carcinoma; NSCLC: Non-small cell lung cancer; OC: Ovarian cancer; BTCC: Bladder transitional cell carcinoma; CRC: Colorectal cancer; HR: Hazard ratio; DFS: Disease-free survival; OS: Overall survival; RFS: Recurrence-free survival.

\section{Correlation of GAS5 expression with clinicopathological features}

The main features of the 15 qualified studies on clinicopathological features are summarized in Table 2. Pooled data results (Table 3) showed that low GAS5 expression was significantly correlated with lymph node metastasis $(\mathrm{OR}=1.92,95 \% \mathrm{CI}: 1.44-2.57, P<0.001)$, distant metastasis $(\mathrm{OR}=2.7,95 \% \mathrm{CI}:$ 1.05-6.97, $P=0.040)$, poor differentiation $(\mathrm{OR}=1.98,95 \% \mathrm{CI}$ : $1.40-2.80, P<0.001)$, larger tumor size $(\mathrm{OR}=3.21,95 \%$ CI: $2.08-4.95, P<0.001)$, and advanced clinical stage $(\mathrm{OR}=0.26,95 \% \mathrm{CI}: 0.18-0.38, P<0.001)$. There was no correlation between decreased GAS5 expression and either gender or age. Due perhaps to the insufficient data, we failed to detect an association between GAS5 expression and other clinicopathological parameters.

\section{Diagnostic value of GAS5 expression}

Five studies, including 477 cancer patients and 366 controls comprising both patients with other diseases and healthy individuals, were used to analyze the diagnostic value of GAS5 expression [13, 23-26]. The main features of the studies are summarized in Table 4. They included data related to four tumor types: NSCLC, HCC, MM, and CRC. The specimens analyzed were serum, in four cases, and tissue in the remaining one. Forest plots depicting sensitivity (SEN) and specificity 
Table 1: Main characteristics of the eligible prognosis studies

\begin{tabular}{ccccccccc}
\hline Study & $\begin{array}{c}\text { Tumor } \\
\text { type }\end{array}$ & $\begin{array}{c}\text { Sample } \\
\text { size }\end{array}$ & Test Method & Cut-off & $\begin{array}{c}\text { Outcome } \\
\text { measure }\end{array}$ & $\begin{array}{c}\text { Analysis } \\
\text { method }\end{array}$ & $\begin{array}{c}\text { HR } \\
\text { estimation }\end{array}$ & $\begin{array}{c}\text { Follow-up } \\
\text { (months) }\end{array}$ \\
\hline Cao 2014 & CC & 102 & qRT-PCR & median value & OS & Multivariate & Direct & $\sim 60$ \\
Sun 2014 & GC & 89 & qRT-PCR & median value & DFS, OS & Multivariate & Direct & $\sim 40$ \\
Tu 2014 & HCC & 71 & qRT-PCR & median value & RFS & Multivariate & Direct & $\sim 60$ \\
Yin 2014 & CRC & 66 & qRT-PCR & median value & OS & Multivariate & Direct & $\sim 60$ \\
Chang 2015 & HCC & 50 & qRT-PCR & median value & OS & Multivariate & Direct & $\sim 60$ \\
Zhang 2015 & NSCLC & 50 & qRT-PCR & median value & OS & Multivariate & Indirect & $\sim 70$ \\
Hu 2016 & HCC & 32 & qRT-PCR & median value & OS & Multivariate & Indirect & $\sim 30$ \\
Li 2016 & OC & 63 & qRT-PCR & median value & DFS, OS & Multivariate & Indirect & $\sim 36$ \\
Meng 2016 & GC & 55 & qRT-PCR & median value & OS & Multivariate & Indirect & $\sim 36$ \\
Zhang 2017 & BTCC & 82 & qRT-PCR & median value & DFS & Multivariate & Direct & $\sim 60$ \\
\hline
\end{tabular}

CC: cervical cancer; GC: gastric cancer; HCC: hepatocellular carcinoma; CRC: colorectal cancer; NSCLC: non-small cell lung cancer; OC: ovarian cancer; BTCC: bladder transitional cell carcinomas; OS: overall survival; DFS: disease free survival; RFS: recurrence-free survival; HR: hazard ratio.

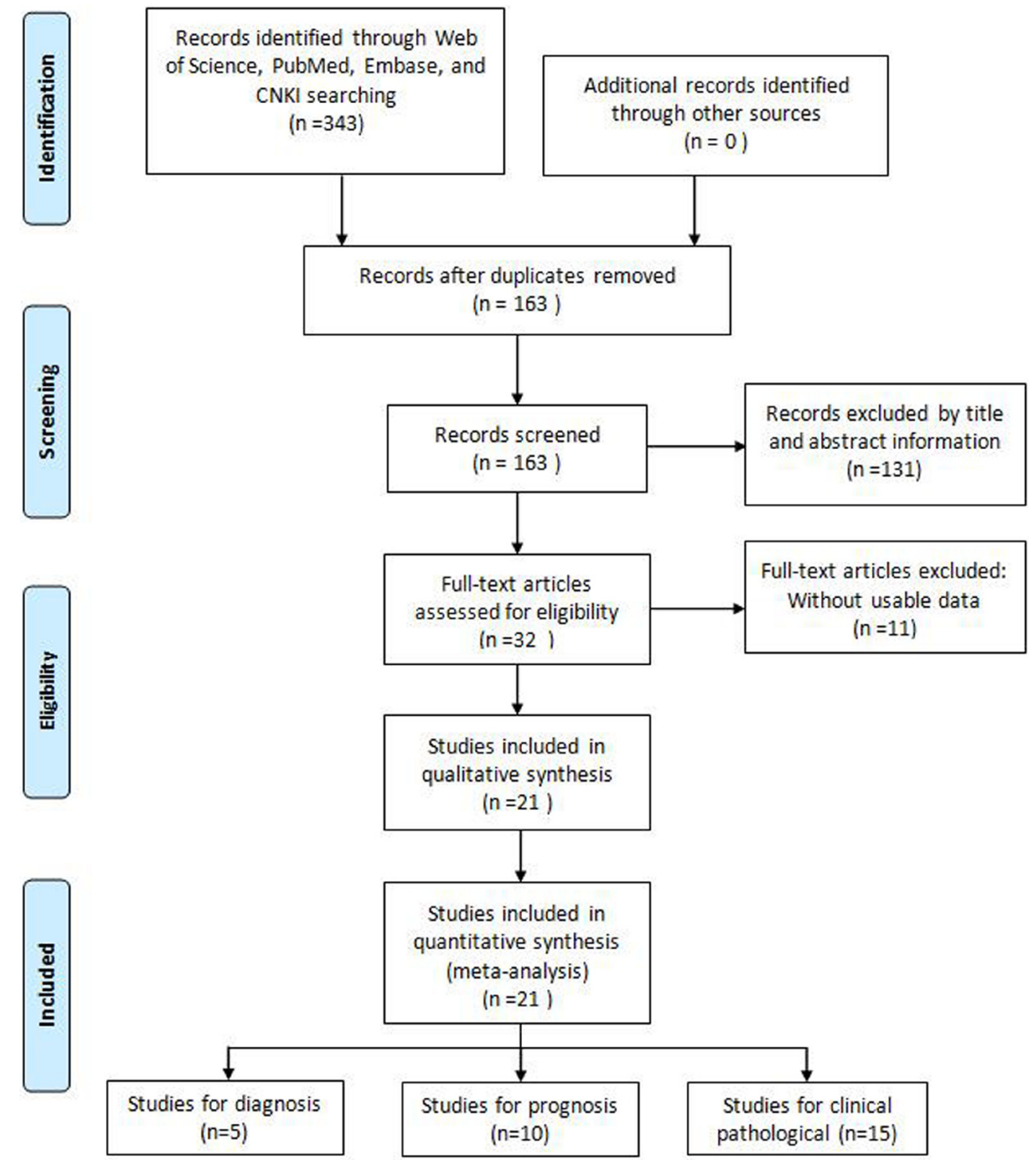

Figure 1: Flow diagram of the literature search and selection. 
Table 2: Main characteristics of the eligible studies that included clinicopathological features

\begin{tabular}{|c|c|c|c|c|c|}
\hline Study & Tumor Type & Sample size & Test Method & Cut-off & Co-variants \\
\hline Shi 2013 & NSCLC & 72 & qRT-PCR & NA & LNM; gender; differentiation; tumor size \\
\hline Cao 2014 & $\mathrm{CC}$ & 102 & qRT-PCR & median value & LNM; differentiation \\
\hline Sun 2014 & $\mathrm{GC}$ & 89 & qRT-PCR & median value & $\begin{array}{l}\text { LNM; DM; differentiation; gender; } \\
\text { tumor size; clinical stage }\end{array}$ \\
\hline Tu 2014 & $\mathrm{HCC}$ & 71 & qRT-PCR & mean value & $\begin{array}{l}\text { LNM; gender; tumor size; clinical stage; } \\
\text { age }\end{array}$ \\
\hline Yin 2014 & CRC & 66 & qRT-PCR & mean value & LNM; DM; gender; age \\
\hline Chang 2015 & $\mathrm{HCC}$ & 50 & qRT-PCR & mean value & Differentiation; gender; tumor size \\
\hline Dong 2015 & NSCLC & 72 & qRT-PCR & mean ratio & $\begin{array}{l}\text { LNM; DM; differentiation; gender; } \\
\text { clinical stage; age }\end{array}$ \\
\hline Gao 2015 & $\mathrm{OC}$ & 60 & qRT-PCR & NA & LNM; differentiation \\
\hline Нu 2016 & $\mathrm{HCC}$ & 32 & qRT-PCR & mean value & Gender; clinical stage \\
\hline Li 2016 & $\mathrm{OC}$ & 63 & qRT-PCR & median ratio & $\begin{array}{l}\text { LNM; DM; differentiation; tumor size; } \\
\text { clinical stage }\end{array}$ \\
\hline Meng 2016 & $\mathrm{GC}$ & 55 & qRT-PCR & NA & $\begin{array}{l}\text { LNM; differentiation; gender; age; tumor } \\
\text { size; clinical stage }\end{array}$ \\
\hline Wu 2016 & NSCLC & 48 & qRT-PCR & NA & LNM; differentiation; gender \\
\hline Xue 2016 & $\mathrm{PC}$ & 118 & qRT-PCR & median ratio & Clinical stage \\
\hline Li 2017 & $\mathrm{CRC}$ & 24 & qRT-PCR & NA & LNM; gender; clinical stage \\
\hline Tan 2017 & NSCLC & 80 & qRT-PCR & Youden index & LNM; gender; age; clinical stage \\
\hline
\end{tabular}

NSCLC: Non-small cell lung cancer; CC: Cervical cancer; GC: Gastric cancer; HCC: Hepatocellular carcinoma; CRC: Colorectal cancer; OC: Ovarian cancer; PC: Prostate cancer; LNM: Lymph node metastasis; DM: Distant metastasis; NA: not available.

\begin{tabular}{|c|c|c|c|}
\hline \multicolumn{2}{|l|}{$\begin{array}{l}\text { Study } \\
\text { ID }\end{array}$} & \multirow[t]{2}{*}{$\mathrm{HR}(95 \% \mathrm{Cl})$} & $\begin{array}{l}\% \\
\text { Weight }\end{array}$ \\
\hline \multicolumn{3}{|l|}{ Overall survival } & \\
\hline Cao 2014 & $\rightarrow$ & $3.22(1.68,6.96)$ & 18.03 \\
\hline Sun 2014 & $\rightarrow$ & $2.43(1.29,4.59)$ & 22.55 \\
\hline Yin 2014 & & \multicolumn{2}{|c|}{$27.80(1.28,500.00) .02$} \\
\hline Chang 2015 & 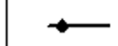 & $3.26(2.42,8.84)$ & 21.62 \\
\hline Zhang 2015 & & $2.17(0.97,5.26)$ & 12.71 \\
\hline Hu 2016 & & $1.64(0.68,7.14)$ & 6.57 \\
\hline Li 2016 & & $2.08(1.01,7.93)$ & 8.56 \\
\hline Meng 2016 & & $1.30(0.91,6.83)$ & 8.94 \\
\hline Subtotal (l-squared $=0.0 \%, p=0.542)$ & $\diamond$ & $2.50(1.85,3.38)$ & 100.00 \\
\hline \multicolumn{4}{|l|}{ Disease free survival } \\
\hline Sun 2014 & $\rightarrow$ & $2.15(1.21,3.80)$ & 37.68 \\
\hline Li 2016 & $\longrightarrow$ & $3.03(1.32,7.36)$ & 16.71 \\
\hline Zhang 2017 & 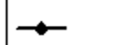 & $2.07(1.23,3.48)$ & 45.62 \\
\hline Subtotal (l-squared $=0.0 \%, p=0.747)$ & $\diamond$ & $2.24(1.58,3.18)$ & 100.00 \\
\hline \multicolumn{4}{|l|}{ Recurrence-free survival } \\
\hline Tu 2014 & $\rightarrow$ & $2.40(1.28,4.59)$ & 100.00 \\
\hline Subtotal $(l-$ squared $=. \%, p=)$. & & $2.40(1.27,4.54)$ & 100.00 \\
\hline 1 & \\
\hline .002 & 1 & \multicolumn{2}{|c|}{00} \\
\hline
\end{tabular}

Figure 2: Forest plot for the relationships between decreased GAS5 expression and OS /DFS/RFS. 
Meta-analysis fixed-effects estimates (exponential form)

Study ommited

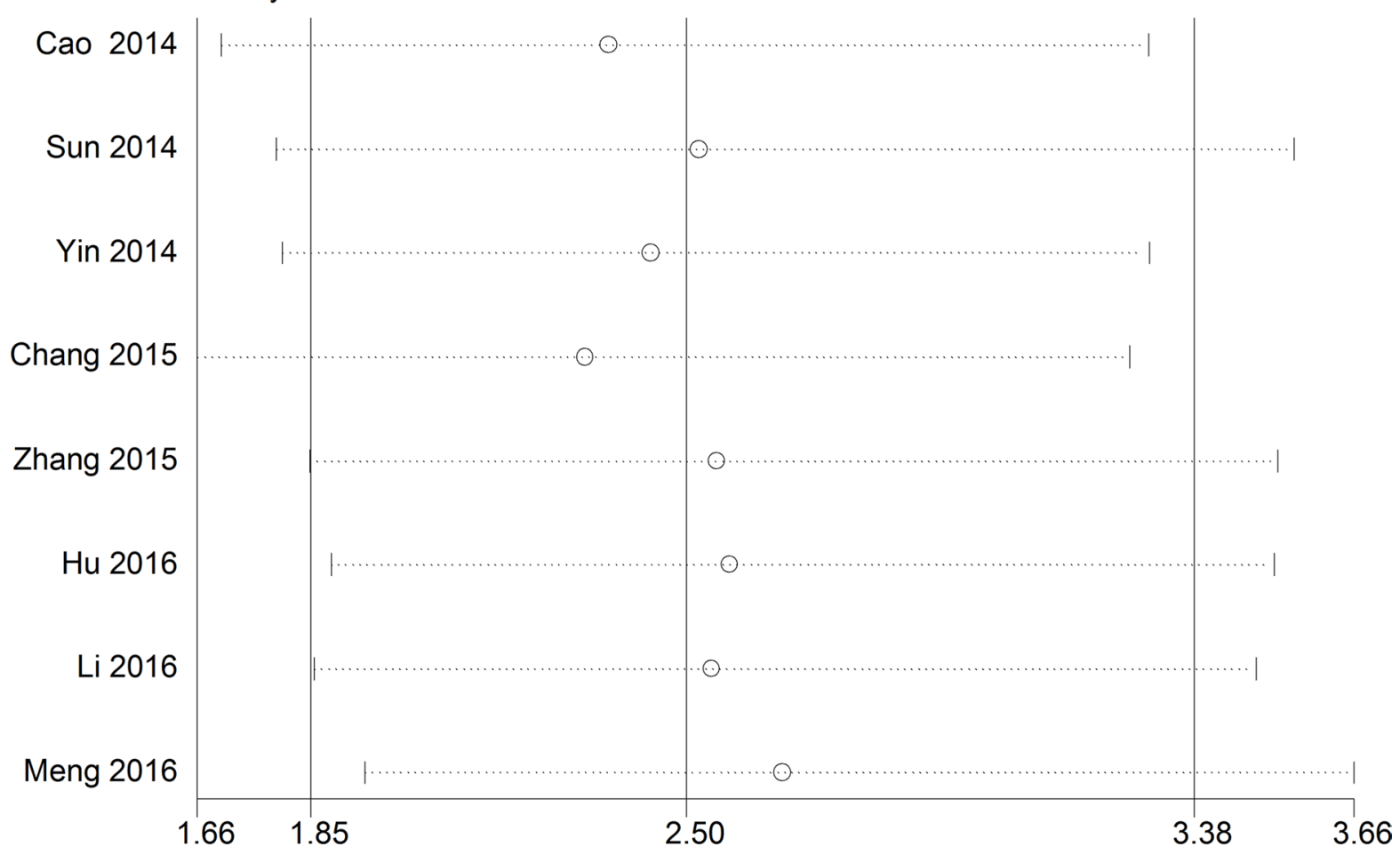

Figure 3: The sensitivity analysis for the meta-analysis of OS in tumor patients.

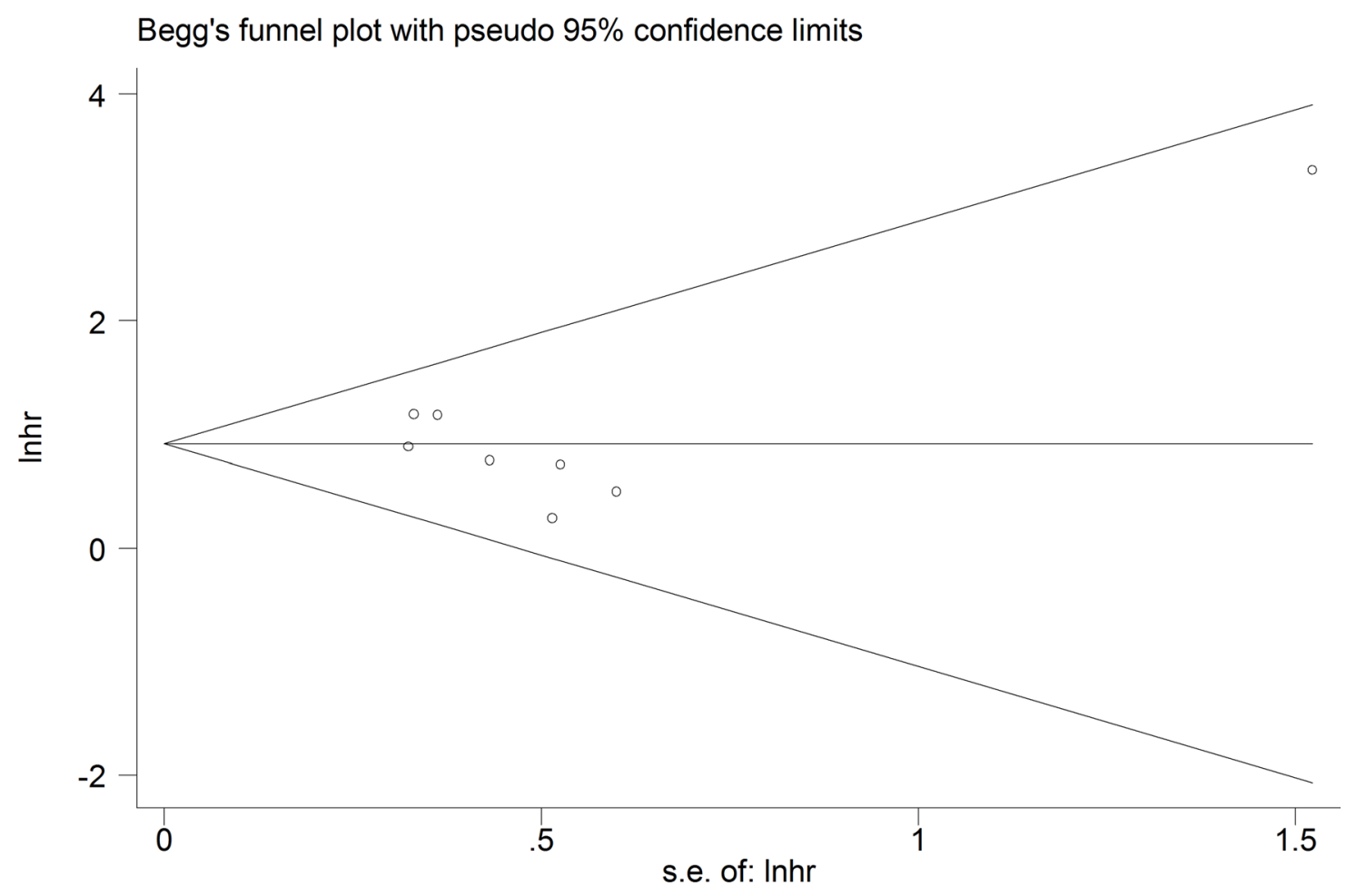

Figure 4: Funnel plot analysis of potential publication bias for meta-analysis of OS in tumor patients. 
Table 3: Meta-analysis results of the correlation of decreased GAS5 expression with clinicopathological parameters

\begin{tabular}{|c|c|c|c|c|c|}
\hline \multirow{2}{*}{ Clinicopathological parameter } & \multirow{2}{*}{ Sample size } & \multirow{2}{*}{ OR $(95 \% \mathrm{CI})$} & \multirow{2}{*}{$P$} & \multicolumn{2}{|c|}{ Heterogeneity } \\
\hline & & & & $I^{2}$ & $P_{h}$ \\
\hline $\begin{array}{l}\text { Age } \\
(\geq 60 \text { vs. }<60)\end{array}$ & 344 & $0.90(0.58-1.40)$ & 0.645 & $9.9 \%$ & 0.350 \\
\hline $\begin{array}{l}\text { Gender } \\
\text { (Male vs. Female) }\end{array}$ & 659 & $1.43(0.98-2.00)$ & 0.059 & $0.0 \%$ & 0.917 \\
\hline $\begin{array}{l}\text { Clinical stage } \\
\text { (I/II vs. III/IV) }\end{array}$ & 604 & $0.26(0.18-0.38)$ & $<0.001$ & $0.0 \%$ & 0.608 \\
\hline $\begin{array}{l}\text { Differentiation } \\
\text { (Poor vs. Well/Moderate) }\end{array}$ & 602 & $1.98(1.40-2.80)$ & $<0.001$ & $48.4 \%$ & 0.050 \\
\hline $\begin{array}{l}\text { Lymph node metastasis } \\
\text { (Yes vs. No) }\end{array}$ & 802 & $1.92(1.44-2.57)$ & $<0.001$ & $77.6 \%$ & $<0.001$ \\
\hline $\begin{array}{l}\text { Distant metastasis } \\
\text { (Yes vs. No) }\end{array}$ & 290 & $2.7(1.05-6.97)$ & 0.040 & $2.4 \%$ & 0.38 \\
\hline $\begin{array}{l}\text { Tumor size } \\
(\geq 5 \mathrm{~cm} \text { vs. }<5 \mathrm{~cm})\end{array}$ & 395 & $3.21(2.08-4.95)$ & $<0.001$ & $13.9 \%$ & 0.325 \\
\hline
\end{tabular}

(SPE) of GAS5 expression for tumor diagnosis are shown in Figure 6. Significant heterogeneity among the studies was observed with respect to both sensitivity and specificity $\left(\mathrm{I}^{2}=86.60 \%\right.$ and $\mathrm{I}^{2}=84.83 \%$, respectively $)$, hence a random-effects model was applied to summarize the diagnostic parameters. Pooled SEN and SPE values were $0.76(95 \% \mathrm{CI}, 0.65-0.85)$ and $0.64(95 \% \mathrm{CI}, 0.52-$ $0.74)$, respectively. Pooled positive likelihood ratio (PLR), negative likelihood ratio (NLR), and overall diagnostic odds ratio (DOR) were 2.1 (95\%CI: $1.6-$ 2.8), 0.37 (95\%CI: $0.25-0.55)$, and 6 (95\% CI: 3-10), respectively. The area under the summary receiver operating characteristic (SROC) curve (AUC) was 0.76 $(95 \%$ CI, $0.72-0.80)$ (Figure 7). These results highlight a potential diagnostic value for lncRNA GAS5. No evidence of publication bias was detected by Deeks' funnel plot $(P>0.05)$ among the studies (Figure 8$)$. Subsequently, we performed meta-regression and subgroup analysis based on tumor distribution and sample and tumor types (Figure 9). We found that both sample and tumor types were unlikely to affect the overall diagnostic accuracy. However, results suggest that downregulated GAS5 expression may help diagnose lung tumors with higher specificity.

\section{DISCUSSION}

Abnormal expression of lncRNAs has been linked to tumorigenesis and tumor progression, and is highly correlated to clinical outcome in several types of cancers [6, 27-29]. GAS5, a prominent non-protein coding RNA gene, is down-regulated in a wide variety of cancer cells and tumor tissues, and has been ascribed tumor suppressor functions [4-6, 10, 15, 21, 30]. GAS5 participates in tumor development by interacting with diverse molecular partners. For instance, GAS5 inhibits the growth of melanoma cells by promoting miR-137 transcription [30], and its upregulation suppresses cell proliferation and promotes apoptosis of human glioma cells by inhibiting miR-222 expression [31]. In gastric cancer cells, GAS5 was reported to inhibit proliferation by upregulation of p21 and suppression of CDK6 [32]. In addition, downregulation of GAS5 has been associated with chemoresistance in some malignant neoplasms, by affecting the sensitivity to adriamycin in gastric cancer [33], trastuzumab in breast cancer [34], mTOR inhibition in prostate cancer [35], and EGFR tyrosine kinase inhibition in wide-type EGFR NSCLC [20]. This evidence indicates that GAS5 can act as a common molecular marker for monitoring the effect of chemotherapy in several tumor types.

To analyze the results of previous studies evaluating the relationship of GAS5 expression with cancer diagnosis, clinicopathological parameters, and prognosis, we implemented this comprehensive meta-analysis. A total of 21 eligible studies, addressing 8 common cancer types, met the selection requirements for inclusion. Survival data comprised OS, DFS, and RFS. The results indicated that decreased GAS5 expression is significantly correlated with unfavorable clinical prognosis in patients with various tumor types. First, pooled results demonstrated that decreased GAS5 expression was associated with a shorter OS time, suggesting that GAS5 may serve as a potential independent predictive biomarker for OS in cancer patients. Second, reduced GAS5 levels were significantly associated with unfavorable DFS or RFS. Third, aggregated results indicated that decreased GAS5 expression was positively correlated with poor tumor 
Table 4: Summary of GAS5 expression levels as diagnostic cancer biomarker

\begin{tabular}{ccccccccc}
\hline \multirow{2}{*}{ Study } & \multirow{2}{*}{ Tumor type } & \multicolumn{2}{c}{ Sample size } & \multirow{2}{*}{ SE (\%) } & \multirow{2}{*}{ SP (\%) } & AUC & 95\%CI & Sample \\
\cline { 3 - 6 } & & Cases & Controls & & & & & \\
\hline Liang 2016 & NSCLC & 90 & 33 & 82.2 & 72.7 & 0.832 & $0.754-0.893$ & Serum \\
Li C 2016 & MM & 60 & 60 & 42 & 79 & 0.782 & $0.700-0.864$ & Serum \\
Zhang 2016 & HCC & 117 & 129 & 87.7 & 48.5 & 0.734 & $0.673-0.796$ & Serum \\
Tan 2017 & NSCLC & 111 & 78 & 42.31 & 77.78 & 0.638 & $0.515-0.760$ & Serum \\
Tian 2017 & CRC & 99 & 66 & 81.9 & 78.2 & 0.773 & $0.484-0.933$ & Tissue \\
\hline
\end{tabular}

NSCLC: Non-small cell lung cancer; MM: Multiple myeloma; HCC: Hepatocellular carcinoma; CRC: Colorectal cancer.

differentiation, larger tumor size, and advanced clinical stage. In addition, cancer patients with low GAS5 expression in tumor tissues were more prone to develop LNM and DM. These results indicate that GAS5 could be a useful biomarker for LNM and DM at early tumor stages. However, due to the paucity of studies available in this regard, this conclusion should be further verified.

In diagnostic analyses of tumor biomarkers, a PLR greater than 10 and an NLR lower than 0.1 generally denote satisfactory diagnostic performance [36]. The aggregated PLR and NLR obtained in our analysis
(2.1 and 0.37) suggest that GAS5 expression has at best moderate accuracy in cancer diagnosis. Due to the significant heterogeneity observed during pooled analysis of sensitivity and specificity, we executed subgroup analyses on tumor distribution, and sample and tumor types. The results showed that sample source and tumor types were unlikely to affect the diagnostic accuracy of GAS5. However, we found that GAS5 expression may be a more specific diagnostic biomarker of lung cancer, compared with other neoplasms. The AUC of 0.76 calculated for GAS5 in tumor diagnosis also suggests
Study ID

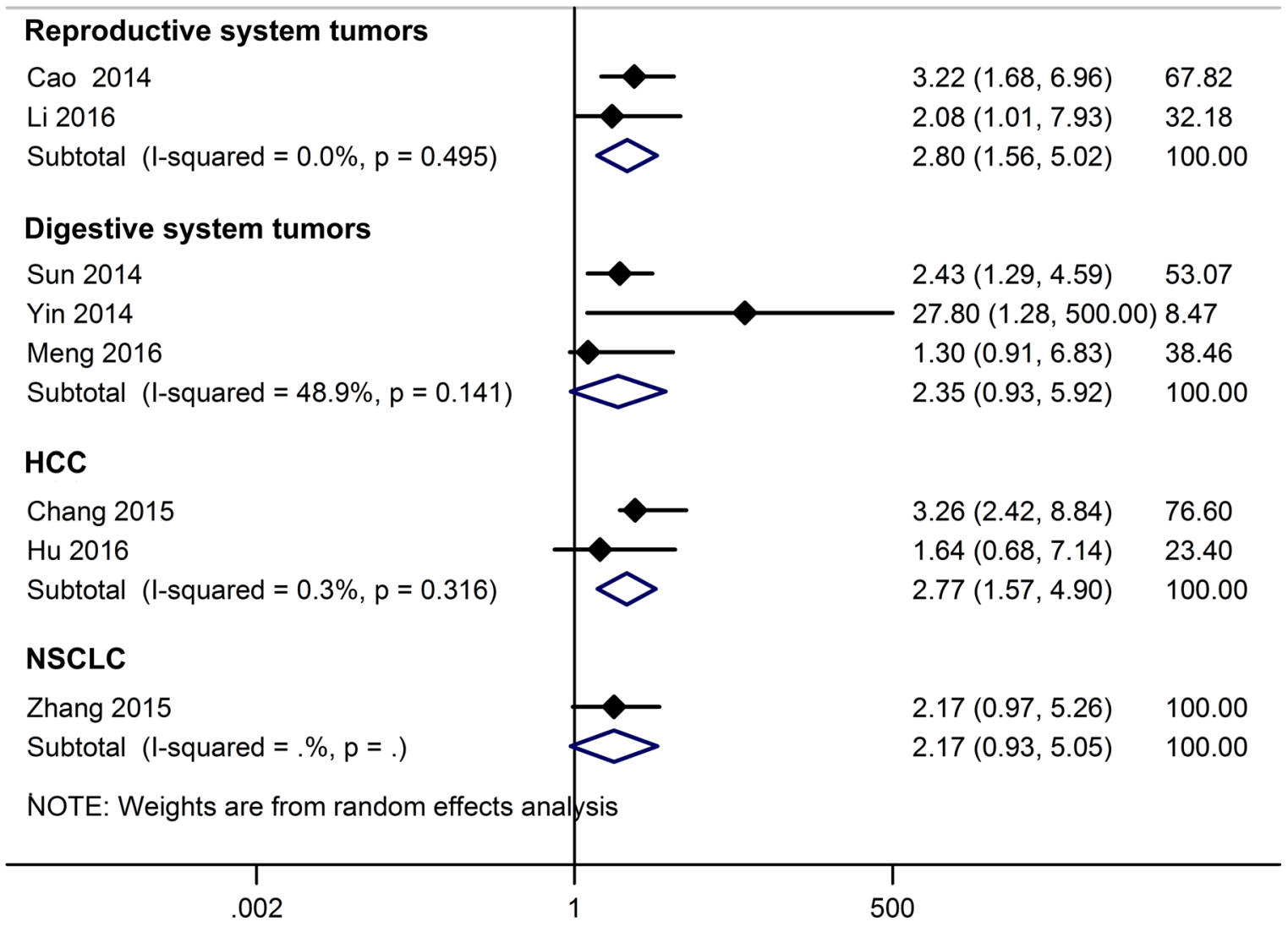

Figure 5: Subgroup analyses for OS according to cancer type. 


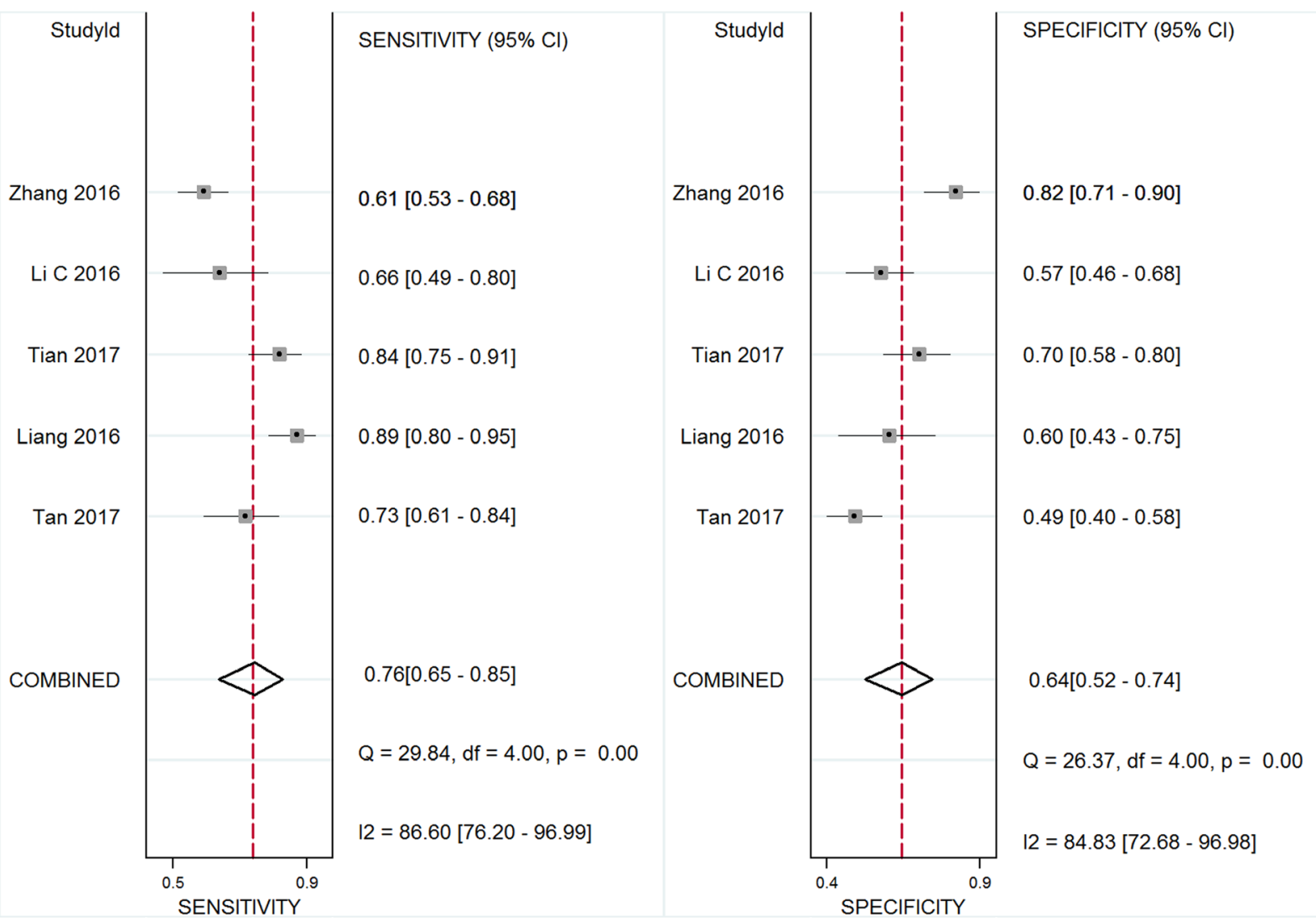

Figure 6: Forest plot of sensitivity and specificity of GAS5 for the diagnosis of cancers.

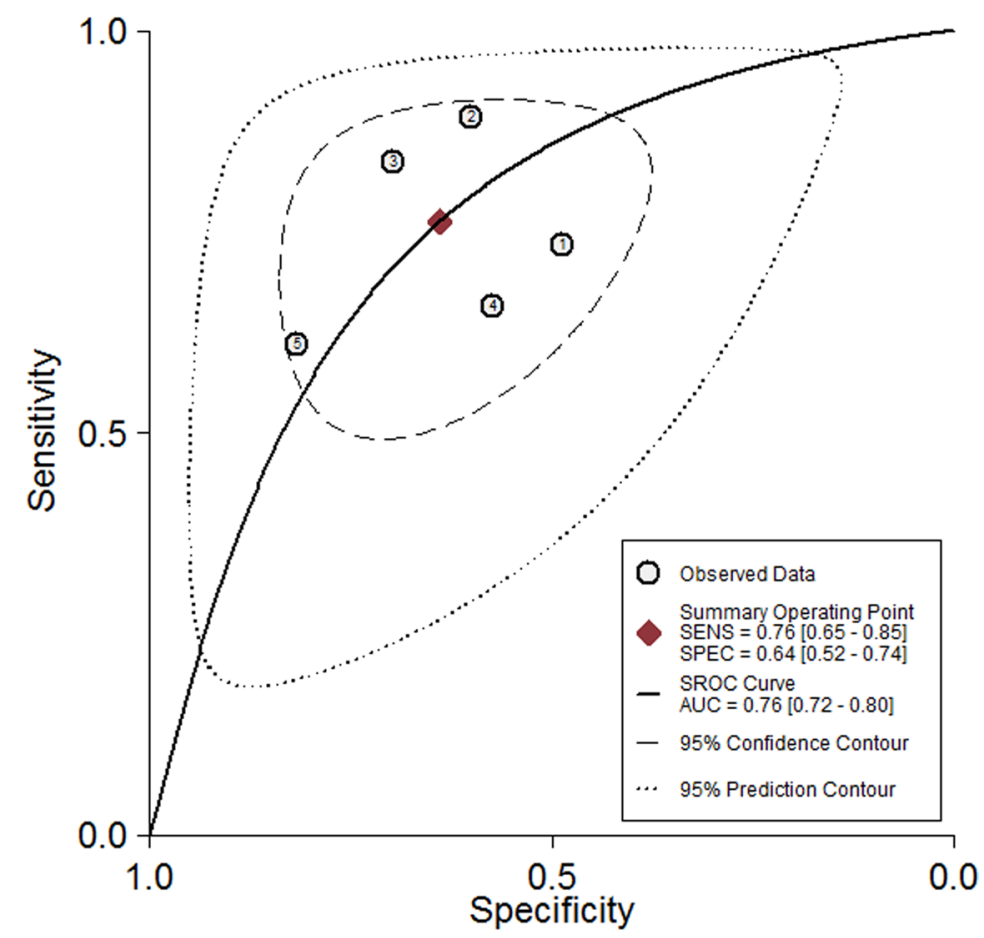

Figure 7: The pooled receiver operating characteristic (SROC) curve based on GAS5. 
moderate diagnostic value. According to published research, improved diagnostic efficacy could be achieved by combining expression data for diverse lncRNAs. For instance, Li et al. [25] found that GAS5 and CRNDE-h combined have a higher positive diagnostic rate for patients with multiple myeloma than GAS5 or CRNDE-h alone. Also, a higher pooled AUC was computed for the combination of IncRNA-LET, PANDAR, PVT1, linc00963, and PTENP1, compared to each of those lncRNAs alone [37]. Strategies like these may prove to be a more successful approach to determine both common and disease-specific molecular markers for tumor diagnosis.

Our meta-analysis presents some limitations that are worth examining. First, the number of original research studies and the total sample size included in our metaanalysis were relatively small, so more qualified studies are needed to perform a more thorough study. Second, since all the included cancer patients were Asians from China, our meta-analysis lacks clinical data from other races, needed to generalize our conclusions. Thirdly, some HRs and their corresponding 95\%CIs were extracted from Kaplan-Meier curves, and may be less reliable than those directly obtained from survival data. Finally, given the significant heterogeneity detected in the analysis of the diagnostic value of GAS5 expression, and the limited diagnostic capability hence derived, further basic and analytical research is warranted to confirm and validate the present results.

In conclusion, our meta-analysis indicates that decreased GAS5 expression is positively correlated with poor tumor differentiation, larger tumor size, and advanced clinical stage. Furthermore, our results suggest that low GAS5 expression is a risk factor for LNM and DM in diverse cancers. Well designed, larger-size, and higherquality basic studies need to be conducted to validate the clinical value of GAS5 as a diagnostic and prognostic cancer marker.

\section{MATERIALS AND METHODS}

\section{Literature search strategy}

A literature search (up to March 20, 2017) was conducted on the online electronic databases Embase, PubMed, Web of Science and CNKI. Search keywords or

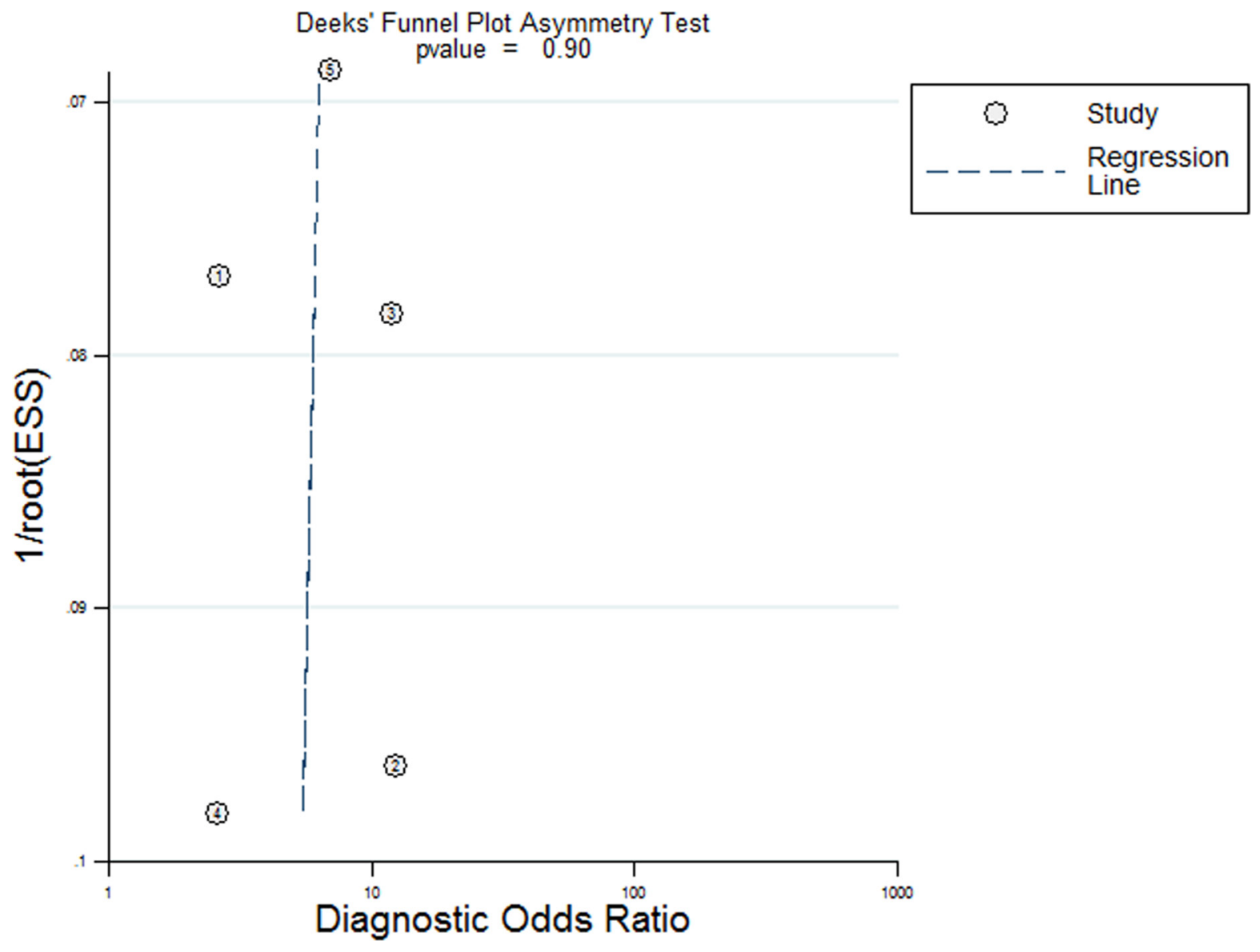

Figure 8: Deeks funnel plot for evaluation publication bias. 
their combinations were: "GAS-5 OR GAS 5 OR growth arrest-specific 5" AND "cancer OR carcinoma OR tumor OR tumour OR neoplasm OR gliomas OR angiosarcoma OR lymphoma OR melanoma OR leukemia”. Only articles in English or Chinese were included in this study.

\section{Study selection criteria}

The criteria for study inclusion in this meta-analysis were as follows: (1) studies evaluating the association of GAS5 with clinicopathological features, with expression levels of GAS5 divided into two groups: high or low; or (2) studies that detected GAS5 levels in serum or tissue and contained adequate data to construct a two by two diagnostic table; or (3) studies that provided sufficient data for computation of odds ratio (OR) or hazard ratio
(HR) with 95\% confidence interval (CI), and KaplanMeier curves or, if unavailable, pertinent data obtained by contacting the corresponding authors.

The study exclusion criteria included the following: (1) duplicate articles; (2) case reports, letters, expert opinions, commentaries, editorials, and reviews; (3) studies without available data; (4) sample cases fewer than 30; (5) non-human research.

\section{Data extraction}

Two investigators (Wei Li and $\mathrm{Na} \mathrm{Li)} \mathrm{independently}$ extracted and reviewed the data from each eligible study. Data collected included first author's name, publication date, study location, tumor type, tumor stage, GAS5 expression detection method, assessment criteria for
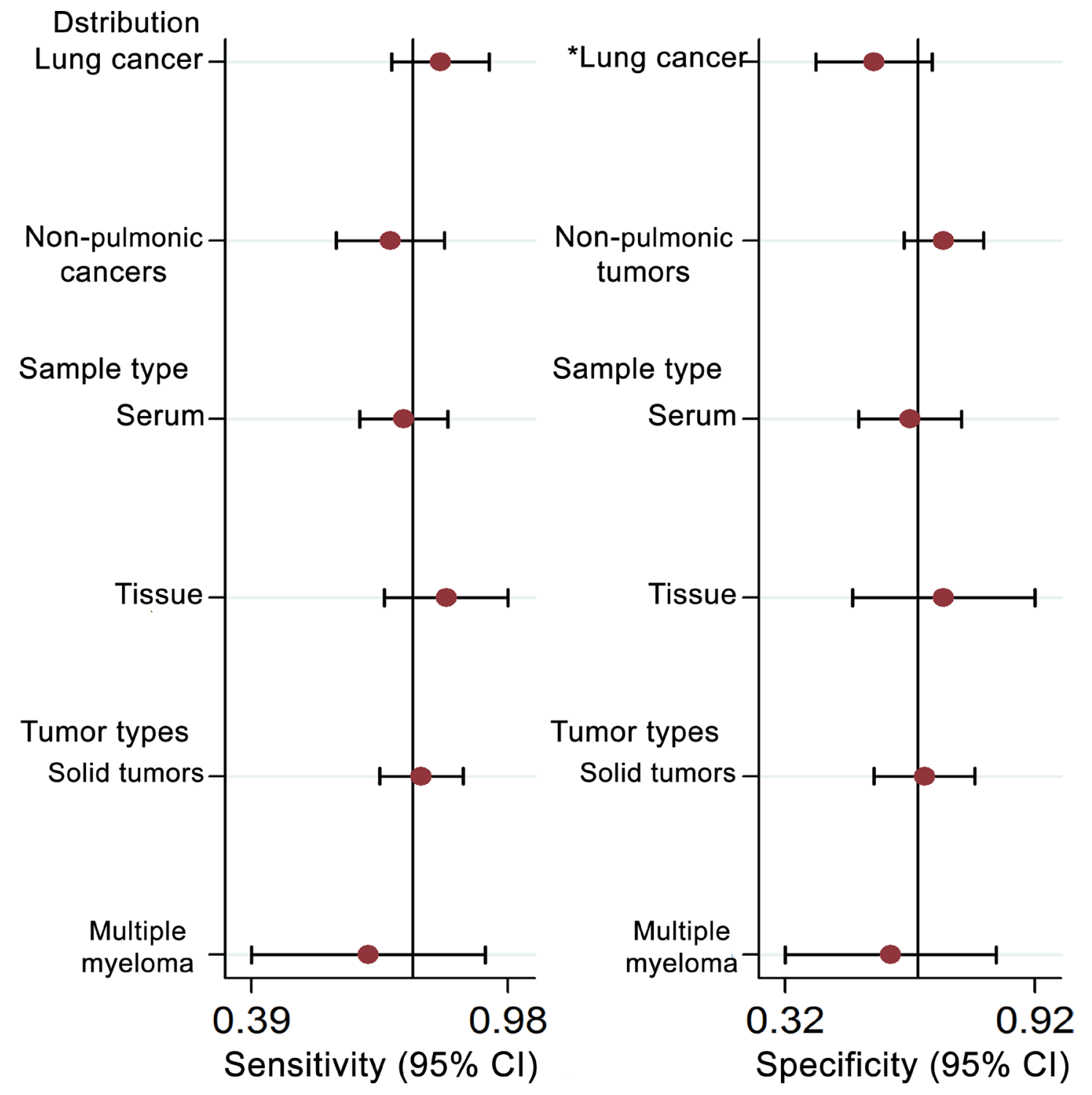

Figure 9: Univariate meta-regression and subgroup analysis for sensitivity and specificity of GAS-5 for the diagnosis of cancers $(* P<0.05)$. 
GAS5 expression, sample size, total patient number, number of patients in the high and low GAS5 expression groups, number of patients with lymph node metastasis (LNM) and distant metastasis (DM) in each group, survival data analysis, follow-up period, sample sizes and statistical results (sensitivity, specificity, AUC) for diagnostic/prognostic analyses and two by two table construction, and OR/HR and corresponding 95\% CI. If the articles did not show survival data, a request was made to the corresponding authors, or data were extracted from survival plots, with HRs estimated by using Engauge Digitizer v.4.1 software as previously described [38, 39].

\section{Statistical methods}

The STATA 12.0 software (Stata, College Station, Texas) was used to perform all statistical analyses. GAS5 expression was categorized into a high expression and a low expression group according to the original published articles. Heterogeneity among the included studies was determined using the I-squared statistic, with $\mathrm{I}^{2}$ values greater than $50 \%$ suggesting that substantial heterogeneity was present. A fixed effects model was used to analyze the pooled results when the included studies showed moderate heterogeneity $\left(\mathrm{I}^{2}<50 \%\right)$. Otherwise, a random effects model was employed $\left(\mathrm{I}^{2}>50 \%\right)$. Sensibility analysis was conducted to evaluate the robustness of the overall results. Begg's funnel plot was used to assess for potential publication bias. For the prognosis meta-analysis, the $\ln (\mathrm{HR})$ and standard error were used to integrate survival results. Also, sensitivity, specificity, PLR, NLR, DOR, SROC curve, and AUC tests and measures were applied to assess the diagnostic accuracy of GAS5. Meta-regression and subgroup analysis were utilized to investigate the origin of heterogeneity. All the $P$-values were determined by a 2 -tailed test and $P<0.05$ was regarded as statistically significant.

\section{ACKNOWLEDGMENTS}

This work was supported by funding from the National Natural Science Foundation of China (Grant No. 81572284).

\section{CONFLICTS OF INTEREST}

The authors declare that there are no conflicts of interest.

\section{REFERENCES}

1. Schneider C, King RM, Philipson L. Genes specifically expressed at growth arrest of mammalian cells. Cell. 1988; 54:787-793.

2. Kino T, Hurt DE, Ichijo T, Nader N, Chrousos GP. Noncoding RNA gas5 is a growth arrest- and starvation- associated repressor of the glucocorticoid receptor. Sci Signal. 2010; 3:ra8.

3. Mourtada-Maarabouni M, Hedge VL, Kirkham L, Farzaneh F, Williams GT. Growth arrest in human T-cells is controlled by the non-coding RNA growth-arrest-specific transcript 5 (GAS5). J Cell Sci. 2008; 121:939-946.

4. Li J, Huang H, Li Y, Li L, Hou W, You Z. Decreased expression of long non-coding RNA GAS5 promotes cell proliferation, migration and invasion, and indicates a poor prognosis in ovarian cancer. Oncol Rep. 2016; 36:3241-3250.

5. Gao J, Liu M, Zou Y, Mao M, Shen T, Zhang C, Song S, Sun M, Zhang S, Wang B, Zhu D, Li P. Long non-coding RNA growth arrest-specific transcript 5 is involved in ovarian cancer cell apoptosis through the mitochondria-mediated apoptosis pathway. Oncol Rep. 2015; 34:3212-3221.

6. Xue D, Zhou C, Lu H, Xu R, Xu X, He X. LncRNA GAS5 inhibits proliferation and progression of prostate cancer by targeting miR-103 through AKT/mTOR signaling pathway. Tumour Biol. 2016; 37:16187-16197.

7. Pickard MR, Mourtada-Maarabouni M, Williams GT. Long non-coding RNA GAS5 regulates apoptosis in prostate cancer cell lines. Biochim Biophys Acta. 2013; 1832:1613-16123.

8. Shi X, Sun M, Liu H, Yao Y, Kong R, Chen F, Song Y. A critical role for the long non-coding RNA GAS5 in proliferation and apoptosis in non-small-cell lung cancer. Mol Carcinog. 2015; 54:E1-E12.

9. Zhang XJ, Tang HC, Liu C. Expression of long non coding RNA GAS5 and its significance in non-small cell lung cancer. Journal of Clinical Pulmonary Medicine. 2015; 20:239-242.

10. Sun M, Jin FY, Xia R, Kong R, Li JH, Xu TP, Liu YW, Zhang EB, Liu XH, De W. Decreased expression of long noncoding RNA GAS5 indicates a poor prognosis and promotes cell proliferation in gastric cancer. BMC Cancer. 2014; $14: 319$.

11. Meng FF, Si JL, Xie XJ, Liu L, Qi YQ, Lv M. Expressions of long no-coding RNAs MEG3, GAS5 in gastric cancer tissues and their association with prognosis of gastric cancer patients. Chinese Journal of Clinical Research. 2016; 29:1449-1452.

12. Yin D, He X, Zhang E, Kong R, De W, Zhang Z. Long noncoding RNA GAS5 affects cell proliferation and predicts a poor prognosis in patients with colorectal cancer. Med Oncol. 2014; 31: 253.

13. Tian Z, Liu LH, Liao JT. Expression and diagnostic values of lncRNA-Malat-1, p21, and GAS5 in colorectal cancer tissue. Acta Med Univ Sci Technol HuaZhong. 2017; 46:10-14.

14. Chang L, Li C, Lan T, Wu L, Yuan Y, Liu Q, Liu Z. Decreased expression of long non-coding RNA GAS5 indicates a poor prognosis and promotes cell proliferation and invasion in hepatocellular carcinoma by regulating vimentin. Mol Med Rep. 2016; 13:1541-1550.

15. Hu L, Ye H, Huang G, Luo F, Liu Y, Liu Y, Yang X, Shen J, Liu Q, Zhang J. Long noncoding RNA GAS5 suppresses the 
migration and invasion of hepatocellular carcinoma cells via miR-21. Tumour Biol. 2016; 37:2691-2702.

16. Zhang H, Guo Y, Song Y, Shang C. Long noncoding RNA GAS5 inhibits malignant proliferation and chemotherapy resistance to doxorubicin in bladder transitional cell carcinoma. Cancer Chemother Pharmacol. 2017; 79:49-55.

17. Pickard MR, Williams GT. Molecular and Cellular Mechanisms of Action of Tumour Suppressor GAS5 LncRNA. Genes (Basel). 2015; 6:484-499.

18. Cao S, Liu W, Li F, Zhao W, Qin C. Decreased expression of lncRNA GAS5 predicts a poor prognosis in cervical cancer. Int J Clin Exp Pathol. 2014; 7:6776-6783.

19. Tu ZQ, Li RJ, Mei JZ, Li XH. Down-regulation of long non-coding RNA GAS5 is associated with the prognosis of hepatocellular carcinoma. Int J Clin Exp Pathol. 2014; 7:4303-4309.

20. Dong S, Qu X, Li W, Zhong X, Li P, Yang S, Chen X, Shao M, Zhang L. The long non-coding RNA, GAS5, enhances gefitinib-induced cell death in innate EGFR tyrosine kinase inhibitor-resistant lung adenocarcinoma cells with wide-type EGFR via downregulation of the IGF1R expression. J Hematol Oncol. 2015; 8: 43.

21. Wu Y, Lyu H, Liu H, Shi X, Song Y, Liu B. Downregulation of the long noncoding RNA GAS5-AS1 contributes to tumor metastasis in non-small cell lung cancer. Sci Rep. 2016; 6: 31093.

22. Li Y, Li Y, Huang S, He K, Zhao M, Lin H, Li D, Qian J, Zhou C, Chen Y, Huang C. Long non-coding RNA growth arrest specific transcript 5 acts as a tumour suppressor in colorectal cancer by inhibiting interleukin-10 and vascular endothelial growth factor expression. Oncotarget. 2017; 8:13690-13702. https://doi.org/10.18632/oncotarget.14625.

23. Tan Q, Zuo J, Qiu S, Yu Y, Zhou H, Li N, Wang H, Liang C, $\mathrm{Yu} \mathrm{M}, \mathrm{Tu}$ J. Identification of circulating long non-coding RNA GAS5 as a potential biomarker for non-small cell lung cancer diagnosisnon-small cell lung cancer, long noncoding RNA, plasma, GAS5, biomarker. Int J Oncol. 2017; 50:1729-1738.

24. Liang W, Lv T, Shi X, Liu H, Zhu Q, Zeng J, Yang W, Yin J, Song Y. Circulating long noncoding RNA GAS5 is a novel biomarker for the diagnosis of nonsmall cell lung cancer. Medicine (Baltimore). 2016; 95:e4608.

25. Li CL, Ye L, Chen L, Zhao S, Ji FY, Niu F. The value of serum long non coding RNA CRNDE-h and GAS5 in diagnosis of multiple myeloma. Chinese Journal of Laboratory Diagnosis. 2016; 20:1844-1848.

26. Jing W, Luo P, Zhu M, Tu JC. LncRNA GAS5 expression in plasma of patients with hepatocellular carcinoma and its significance in the treatment evaluation. Chinese Journal of Laboratory Medicine. 2016; 39:599-603.

27. Qian Y, Liu D, Cao S, Tao Y, Wei D, Li W, Li G, Pan X, Lei D. Upregulation of the long noncoding RNA UCA1 affects the proliferation, invasion, and survival of hypopharyngeal carcinoma. Mol Cancer. 2017; 16: 68.
28. Su J, Zhang E, Han L, Yin D, Liu Z, He X, Zhang Y, Lin F, Lin Q, Mao P, Mao W, Shen D. Long noncoding RNA BLACAT1 indicates a poor prognosis of colorectal cancer and affects cell proliferation by epigenetically silencing of p15. Cell Death Dis. 2017; 8: e2665.

29. Zhuo W, Kang Y. Lnc-ing ROR1-HER3 and Hippo signalling in metastasis. Nat Cell Biol. 2017; 19:81-83.

30. Bian D, Shi W, Shao Y, Li P, Song G. Long non-coding RNA GAS5 inhibits tumorigenesis via miR-137 in melanoma. Am J Transl Res. 2017; 9:1509-1520.

31. Zhao X, Wang P, Liu J, Zheng J, Liu Y, Chen J, Xue Y. Gas5 Exerts Tumor-suppressive Functions in Human Glioma Cells by Targeting miR-222. Mol Ther. 2015; 23:1899-1911.

32. Guo X, Deng K, Wang H, Xia J, Shan T, Liang Z, Yao L, Jin S. GAS5 Inhibits Gastric Cancer Cell Proliferation Partly by Modulating CDK6. Oncol Res Treat. 2015; 38:362-366.

33. Zhang N, Wang AY, Wang XK, Sun XM, Xue HZ. GAS5 is downregulated in gastric cancer cells by promoter hypermethylation and regulates adriamycin sensitivity. Eur Rev Med Pharmacol Sci. 2016; 20:3199-3205.

34. Li W, Zhai L, Wang H, Liu C, Zhang J, Chen W, Wei Q. Downregulation of LncRNA GAS5 causes trastuzumab resistance in breast cancer. Oncotarget. 2016; 7:27778-2786. https://doi.org/10.18632/oncotarget.8413.

35. Yacqub-Usman K, Pickard MR, Williams GT. Reciprocal regulation of GAS5 lncRNA levels and mTOR inhibitor action in prostate cancer cells. Prostate. 2015; 75:693-705.

36. Hayes DF, Isaacs C, Stearns V. Prognostic factors in breast cancer: current and new predictors of metastasis. J Mammary Gland Biol Neoplasia. 2001; 6:375-392.

37. Wu Y, Wang YQ, Weng WW, Zhang QY, Yang XQ, Gan HL, Yang YS, Zhang PP, Sun MH, Xu MD, Wang CF. A serumcirculating long noncoding RNA signature can discriminate between patients with clear cell renal cell carcinoma and healthy controls. Oncogenesis. 2016; 5:e192.

38. Xiao J, Hu CP, He BX, Chen X, Lu XX, Xie MX, Li W, He SY, You SJ, Chen Q. PTEN expression is a prognostic marker for patients with non-small cell lung cancer: a systematic review and meta-analysis of the literature. Oncotarget. 2016; 7:57832-57840. https://doi.org/10.18632/ oncotarget.11068.

39. Xiao J, He B, Zou Y, Chen X, Lu X, Xie M, Li W, He S, You S, Chen Q. Prognostic value of decreased FOXP1 protein expression in various tumors: a systematic review and meta-analysis. Sci Rep. 2016; 6:30437. 